\title{
Comparative Analysis of Postharvest Antioxidant Capacity and Quality in two Wucai (Brassica Campestris L.) Genotypes
}

\author{
Libing Nie ${ }^{1,2, a}$, Yun Daii, ${ }^{1,2, a}$, Shilei Xie ${ }^{1,2}$, Yushan Zheng ${ }^{1,2}$, Jie Wang ${ }^{1,2}$, Qiang Ji ${ }^{1,2}$, Mengru Zhao ${ }^{1,2}$, Shidong \\ $\mathrm{Zhu}^{1,2,3}$, Jinfeng Hou ${ }^{1,2,3}$, Guohu Chen ${ }^{1,2}$, Chenggang Wang ${ }^{* 1,2,3}$ and Lingyun Yuan*1,2,3 \\ ${ }^{1}$ Vegetable Genetics and Breeding Laboratory, College of Horticulture, Anhui Agricultural University; Hefei 230036, China \\ ${ }^{2}$ Provincial Engineering Laboratory for Horticultural Crop Breeding of Anhui, Hefei 230036, China
}

${ }^{3}$ Wanjiang Vegetable Industrial Technology Institute, Maanshan, Anhui, 238200, China

${ }^{a}$ These authors contributed equally to this work.

*Corresponding author: Lingyun Yuan, College of Horticulture, Anhui Agricultural University, Vegetable Genetics and Breeding Laboratory, 130 West Changjiang Road, 230036 Hefei, Anhui, China

Chenggang Wang, College of Horticulture, Anhui Agricultural University, Vegetable Genetics and Breeding Laboratory, 130 West Changjiang Road, 230036 Hefei, Anhui, China

\section{ARTICLE INFO \\ Received: 慧 February 15, 2019 \\ Published: 㓞 February 27, 2019}

Citation: Nie L, Dai Y, Xie S, Zheng Y, Wang J, Ji Q, Zhao M, Zhu S, Hou J, Chen G, Wang C, Yuan L. Comparative Analysis of Postharvest Antioxidant Capacity and Quality in two Wucai (Brassica Campestris L.) Genotypes. Biomed J Sci \& Tech Res 15(2)-2019. BJSTR. MS.ID.002676.

Abbreviations: Chl: chlorophyll; Car: Carotenoids; EC: Electronical Conductivity; Vc: Vitamin C; TP: Total Phenol; T-AOC: Total Antioxidant Capacity; PW-2: Purple Leaf; GW-13: Green Leaf

\begin{abstract}
Leafy vegetables are one of the main sources of nutrients to human health. The aim of this study was to investigate the changes in antioxidant capacity and quality in one type leafy vegetable. Wucai (Brassica campestris L.) is originated from China and now is planted world around. In present study, two genotypes with purple leaf (PW-2) or green leaf (GW13) were sampled during postharvest storage for 6 days. Our results showed that low temperature could effectively delay nutrient decline in the leaf. As increasing of storage days, total chlorophyll ( $\mathrm{Chl}$ ) content was markedly decreased at $25^{\circ} \mathrm{C}$ or $4^{\circ} \mathrm{C}$ in two genotypes, while its content was always higher in PW-2 than in GW-13 when exposed to $4^{\circ} \mathrm{C}$. Carotenoids (Car) contents of two genotypes were firstly decreased and then gradually accumulated as storage days prolonged. When preserved at $4{ }^{\circ} \mathrm{C}$, electronical conductivity (EC) of PW-2 was lower than GW-13 after $6 \mathrm{~d}$ storage, which attributed to higher anthocyanin content and total antioxidant capacity (T-AOC). The results showed that low temperature could effectively alleviate nutrient decline in the leaf. The quality of wucai stored at $4^{\circ} \mathrm{C}$, such as vitamin $\mathrm{C}(\mathrm{Vc})$, total free amino acid and total soluble sugar were higher than those stored at $25^{\circ} \mathrm{C}$. Additionally, these quality indices in PW-2 were significantly higher than those in GW-13. It suggested that the nutritional quality of PW-2 could be maintained more than that of GW-13 after postharvest, which demonstrated that low-temperature storage is a useful approach to enhance the content of total soluble sugar, Vc, total phenol (TP), total free amino acid and cellulose and extend the shelf-life of wucai.
\end{abstract}

Keywords: Wucai; Postharvest; Antioxidant capacity; Quality; Storage

\section{Introduction}

People are increasingly concerned about the nutritional value of the foods they consume, and consequently the best cultivation practices are needed to produce crops that contain high functional nutrients [1]. Various postharvest approaches, including lowtemperature storage, biochemical treatments and controlled atmosphere storage, have been used to slow the respiration rate, delay ripening or senescence, and extend shelf life while preserving quality. The most commonly used strategy to maintain the freshness of horticultural products is low-temperature storage [2]. Wucai (Brassica campestris L. ssp. chinensis var. rosularis Tsen et Lee.) belongs to non-heading Chinese cabbage with the beautiful shape and high nutritional value [3]. This crop originated from China and distributed mainly along Yangtze-Huai River basin where it is 
generally cultivated in late fall or winter [4]. It has been given the laudatory name "leaf peony" because of its beautiful shape. Wucai tastes fresh and crisp and is also called the "vitamin" vegetable due to its high Vc content and the presence of other trace nutrients, such as carotene, calcium, iron, phosphorus, and zinc [5].

It is also understood that wucai possesses free sugars, organic acids, amino acids and lipids which are natural components of many vegetables and they play an important role in maintaining vegetable quality and determining nutritive values in the diet [3]. Numerous epidemiological studies indicate that the consumption of Brassicaceae vegetables is linked to a reduced incidence of cancer and cardiovascular diseases. These beneficial effects have been partly credited to the metabolite which has antioxidant activities [6]. However, there are large differences in nutrient substance content between wucai genotypes with different leaf color. The purpose of this study was to investigate the quality and antioxidant activity of two genotypes wucai (green leaf and purple leaf) stored at ambient and low temperatures, focusing on the physiological properties, nutritional quality and antioxidant capacity.

\section{Materials and Methods}

\section{Plant Materials and Storage Conditions}

Two wucai genotypes, GW-13 (green leaf) and PW-2 (purple leaf), were sampled as representative varieties with different leaf color. They have been selected through many generations of systematic breeding, obtained stable genetic characters with better quality and higher yield under favorable conditions. The seeds were obtained from the Vegetable Genetics and Breeding Laboratory at Anhui Agricultural University, China. Seeds were sown in nursery substrate and then moved into a phytotron, which was maintained at $25 \pm 1^{\circ} \mathrm{C}$ (day) and $18 \pm 1^{\circ} \mathrm{C}$ (night) (light/dark 14/10h) with the relative humidity of $70 \%$ and $300 \mu \mathrm{mol} \mathrm{m}^{-2} \mathrm{~s}^{-1}$ photosynthetically active radiation. After 3 weeks, the seedings with four or five true leaves of uniform size were randomly divided into four groups for treatments. The four low-temperature treatments were as follows:

a) $\mathrm{PW}-2$, storage at $25^{\circ} \mathrm{C}$ for 6days;

b) $\mathrm{PW}-2$, storage at $4^{\circ} \mathrm{C}$ for 6 days;

c) $\mathrm{GW}-13$, storage at $25^{\circ} \mathrm{C}$ for 6 days;

d) $\mathrm{GW}-13$, storage at $4^{\circ} \mathrm{C}$ for 6 days.

Samples were collected at 2, 4 and $6 \mathrm{~d}$. Wucai from initial harvest were used as $0 \mathrm{~d}$ sample. Three replicates were employed for the next analysis.

\section{Quantification of Content of Chl, Car and Anthocyanin}

The Chl and Car contents were determined according to the method described by Zou et al. [7] with some modifications. Fresh leaves $(0.2 \mathrm{~g})$ were extracted for $24 \mathrm{~h}$ in the dark at $4^{\circ} \mathrm{C}$ in $25 \mathrm{ml}$ brown volumetric flask of extract buffer (acetone: ethanol: water = 4.5: 4.5: 1). The absorbance at 649, 665 , and $470 \mathrm{~nm}$ was measured after filtration. Chl concentration was calculated using the following formula: Chl $a=13.95 \mathrm{~A}_{665}-6.88 \mathrm{~A}_{649} ; \mathrm{Chl} b=24.96 \mathrm{~A}_{649}-7.32 \mathrm{~A}_{665}$; Chl $a+b=$ Chl $a+$ Chl $b$; Car $=\left(1000 \times \mathrm{A}_{470}-2.05 \times\right.$ Chl $a-114.8 \times$ $\mathrm{Chl} b$ ) / 245. Fresh leaves (1g) were cut into fragments and placed in test tube with $10 \mathrm{ml} 0.1 \mathrm{M} \mathrm{HCl}$. The solution was filtered after being extracted for $4 \mathrm{~h}$ in incubator at $32^{\circ} \mathrm{C}$. The absorbance was read by spectrophotometer at $530 \mathrm{~nm}$, and $0.1 \mathrm{M} \mathrm{HCl}$ was used as blank control. When the absorbance is 0.1 , the anthocyanin concentration is called one unit to compare the relative content of anthocyanin. Multiply the measured absorbance by 10 to represent the unit of relative concentration of anthocyanins.

\section{Determination of EC, TP and T-AOC}

Electrolyte leakage was represented by electronic conductivity (EC) in present study. It was measured according to the method described by Bajji et al. [8] with some modifications. The leaf disks (11 $\mathrm{mm}$ in diameter) were placed in a $20 \mathrm{ml}$ test tube containing $12 \mathrm{ml}$ of deionized water at $25^{\circ} \mathrm{C}$ for $30 \mathrm{~min}$. The conductivity $\left(\mathrm{EC}_{1}\right)$ of the solution was measured with a Thermo Orion STARAHB conductivity meter (Thermo Orion., Waltham, MA, USA). The tubes were then heated in boiling bath for $30 \mathrm{~min}$. After the tubes cooled, solution conductivity $\left(\mathrm{EC}_{2}\right.$ ) was measured with an electrical conductivity meter. EC was calculated according to the formula: $\mathrm{EC}=\mathrm{EC}_{1} / \mathrm{EC}_{2}$. TP content was measured according to the method described as plant total phenol reagent kit (Cat \# BC1340, Beijing Solarbio Science \& Technology Co., Ltd, China). T-AOC was measured according to the method described as T-AOC reagent kit (Cat \# BC1310, Beijing Solarbio Science \& Technology Co., Ltd, China).

\section{Determination of Vc, Total Free Amino Acid, Total Soluble Sugar and Cellulose}

The oxalic acid method was measured for the determination of Vc levels in wucai leaves [9]. The reaction solution was used to assay Vc content using reversed-phase high-performance liquid chromatography. The total free amino acid profile was obtained using an amino acid analyzer (High-speed Amino Acid Analyzer L-8900, Hitachi High-Technologies Corporation, Tokyo, Japan). Soluble sugar content was measured by the method of anthronesulfuric acid colorimetry. Fresh leaves $(0.2 \mathrm{~g})$ were minced and placed in test tube with $10 \mathrm{ml}$ of distilled water, then boiled for 30 min. The extract was filtered and treated with anthrone and sulfuric acid to react in a boiling water bath for $1 \mathrm{~min}$, then cooled to room temperature and read at wavelength of $630 \mathrm{~nm}$. Cellulose content was measured by the method of anthrone ethyl acetate. Dry sample $(100 \mathrm{mg})$ was digested with $60 \%$ sulphuric acid for $30 \mathrm{~min}$ in ice bath. The solution was treated with $2 \%$ anthrone and concentrated sulfuric acid in a test tube, boiled for $10 \mathrm{~min}$ and cooled to room temperature, then read at wavelength of $620 \mathrm{~nm}$. 


\section{Statistical Analysis}

The data were expressed as the mean \pm SD in three replications. Statistical analysis was processed with SPSS 19.0 software (SPSS, Chicago, CA, USA), using Duncan's multiple range test at the $p<0.05$ level of significance. Sigmaplot v10.0 (Systat Software Inc., San Jose, CA, USA) was used for plotting the results.

\section{Results and Discussion}

\section{Pigment Content}

The Chl $a+b$ content of four treatments exhibited declined trends with the increasing of storage period (Figure 1A). However, $\mathrm{Chl} a+b$ content was decreased slowly when stored at $4^{\circ} \mathrm{C}$. The $\mathrm{Chl}$ $a+b$ content was decreased by $50.40 \%$ in PW- 2 after $6 \mathrm{~d}$ at $25^{\circ} \mathrm{C}$ compared to the control, while it was decreased by $59.71 \%$ in GW13. The level of $\mathrm{Chl}$ reduction depends on the variety, production system, cultural practices, storage duration, and temperature [10]. The content of Car was increased with the increase of storage time after stored $2 \mathrm{~d}$ (Figure 1B). After stored at $25^{\circ} \mathrm{C}$ for $6 \mathrm{~d}$, Car content of $\mathrm{PW}-2$ and $\mathrm{GW}-13$ reached its peak level, which was increased by $53.34 \%$ and $67.07 \%$ than that stored at $4{ }^{\circ} \mathrm{C}$, respectively. Car content of PW-2 and GW-13 exhibited firstly decline and then obviously accumulated, which might be due to the significant water loss. In our study, the reduction of pigment in two wucai genotypes stored at $4{ }^{\circ} \mathrm{C}$ was significantly lower than that stored at $25^{\circ} \mathrm{C}$. It suggested low temperature storage significantly slowed down the plant senescence, which was like the previous report in Dendrobium officinale and Psidium guajava [2,11]. Leaf softening and leaf surface decay were observed to a certain extent after storage for $6 \mathrm{~d}$ (Figure 1C-1H). The present results indicated that the Chl content of wucai leaf was gradually reduced during storage process, which can be verified by the color version in two genotypes.

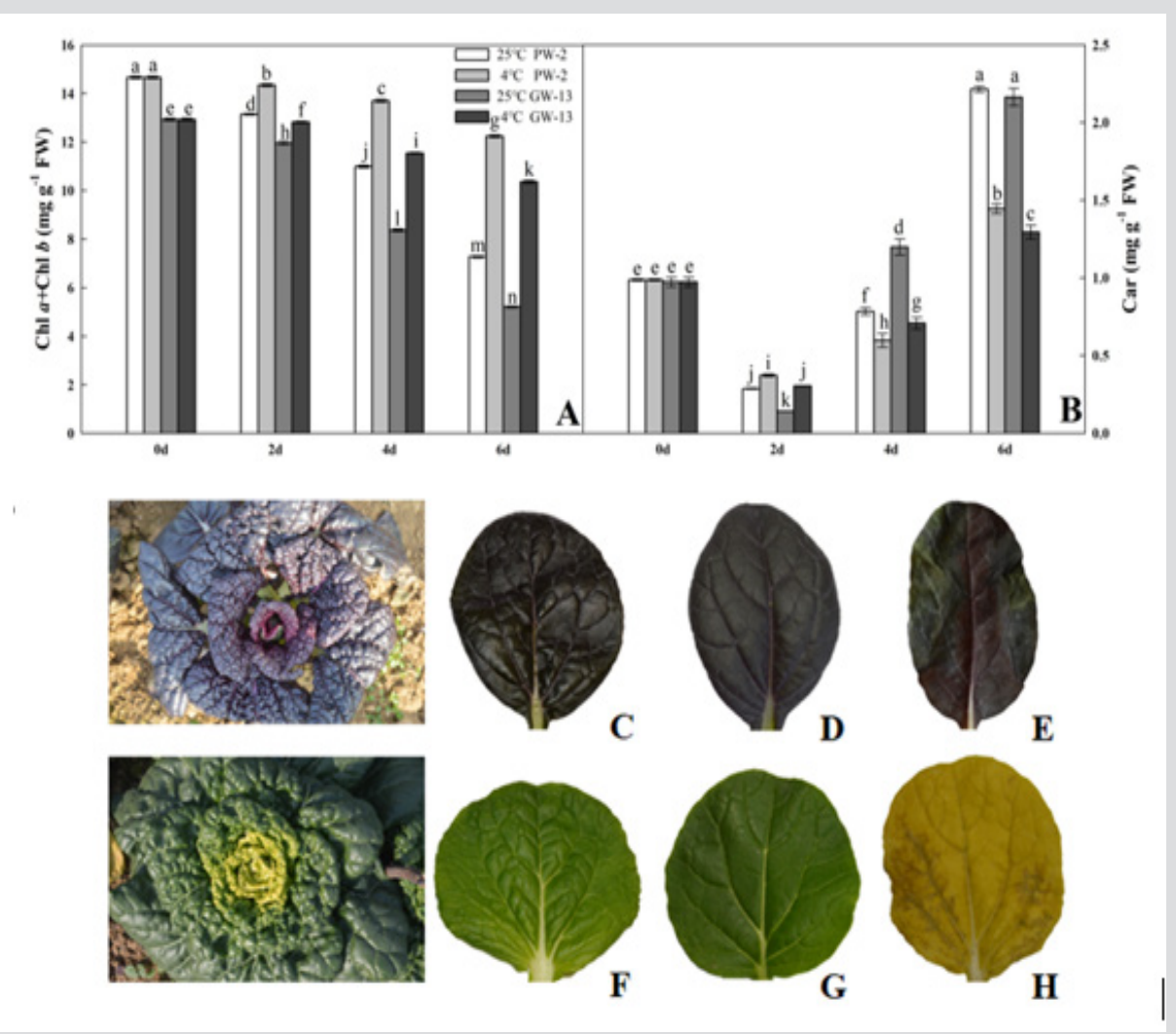

\section{Figure 1:}

A. Changes in the content of $\mathrm{Chl} \mathrm{a}+\mathrm{b}$,

B. Car and leaf color $(\mathrm{C}-\mathrm{H})$ in two wucai genotypes during postharvest storage at different temperatures. Values represent the mean $\pm S E(n=3)$. Letters indicate significant differences at $P<0.05$ according to Duncan's multiple range tests.

C. $\quad 0 \mathrm{~d} P W-2$,

D. $6 \mathrm{~d} 4^{\circ} \mathrm{C} \mathrm{PW}-2$,

E. $\quad 6 \mathrm{~d} 25^{\circ} \mathrm{C} \mathrm{PW}-2$,

F. $0 \mathrm{~d}$ GW-13,

G. $\quad 6 \mathrm{~d} 4^{\circ} \mathrm{C}$ GW-13, and

H. $\quad 6 \mathrm{~d} 25^{\circ} \mathrm{C} \mathrm{GW}-13(\mathrm{H})$. 


\section{Analyses of EC, TP, Relative Anthocyanin Concentration and T-AOC}

EC enables cell membrane injury to be assessed when plants are subjected to cold stress [12]. The EC in two wucai genotypes stored at $4^{\circ} \mathrm{C}$ and $25^{\circ} \mathrm{C}$ were increased with storage period prolonged (Figure 2A), which indicated plasma membrane was degraded gradually during storage. At $6 \mathrm{~d}$, the EC of GW-13 was 4.53 -fold compared with the control at $25^{\circ} \mathrm{C}$, while it was 3.59-foldcompared with the control at $4{ }^{\circ} \mathrm{C}$ in PW-2. Increased rates of solute and electrolyte leakage occur in a variety of chilled tissues and have been used to evaluate membrane damage following chilling [13]. In our study, the EC of two wucai genotypes stored at $0 \mathrm{~d}$ and $2 \mathrm{~d}$ was no significantly difference when they stored at different temperature $\left(4^{\circ} \mathrm{Cor} 25^{\circ} \mathrm{C}\right)$. Furthermore, the EC of GW13 was significantly higher than that of PW-2 at $6 \mathrm{~d}$ under different conditions, which showed the damage degree of membranes in GW13 was higher than that in PW-2. It indicated PW-2 genotype had stronger membrane stability when subjected to $4^{\circ} \mathrm{C}$ storage, which facilitated to resist oxidative stress.
The TP content of PW-2 was always higher than that of GW-13 at 0,2 and $4 \mathrm{~d}$ under all storage conditions (Figure 2B). Compared to $25^{\circ} \mathrm{C}$, the TP content in $\mathrm{PW}-2$ and $\mathrm{GW}-13$ stored at $6 \mathrm{~d}$ were decreased at $4{ }^{\circ} \mathrm{C}$, but it was declined more sharply in GW-13. Furthermore, at $6 \mathrm{~d}$, the TP content of PW-2was markedly higher than that of $\mathrm{GW}-13$ at $4^{\circ} \mathrm{C}$. It indicated antioxidant capacity of PW-2 was higher than that of GW-13. In this study, the content of TP in wucai stored at $25^{\circ} \mathrm{C}$ was increased with the storage period increased, while was increased first then decreased which stored at $4^{\circ} \mathrm{C}$ (Figure $2 \mathrm{~B}$ ). The presence of phenols point to the existence of an antioxidant activity of the biological system, especially regarding their oxidation-reduction properties [10]. The relative anthocyanin concentration in PW-2 was higher than that in GW13 even under normal condition (Figure 2C). For the PW-2, the relative anthocyanin concentration was decreased with the storage period increased, but when it stored at $4^{\circ} \mathrm{C}$, the down trend was slower compared with it stored at $25^{\circ} \mathrm{C}$. After stored $6 \mathrm{~d}$, the relative anthocyanin concentration of $\mathrm{PW}-2$ stored at $4{ }^{\circ} \mathrm{C}$ was $49.31 \%$ higher than it stored at $25^{\circ} \mathrm{C}$.

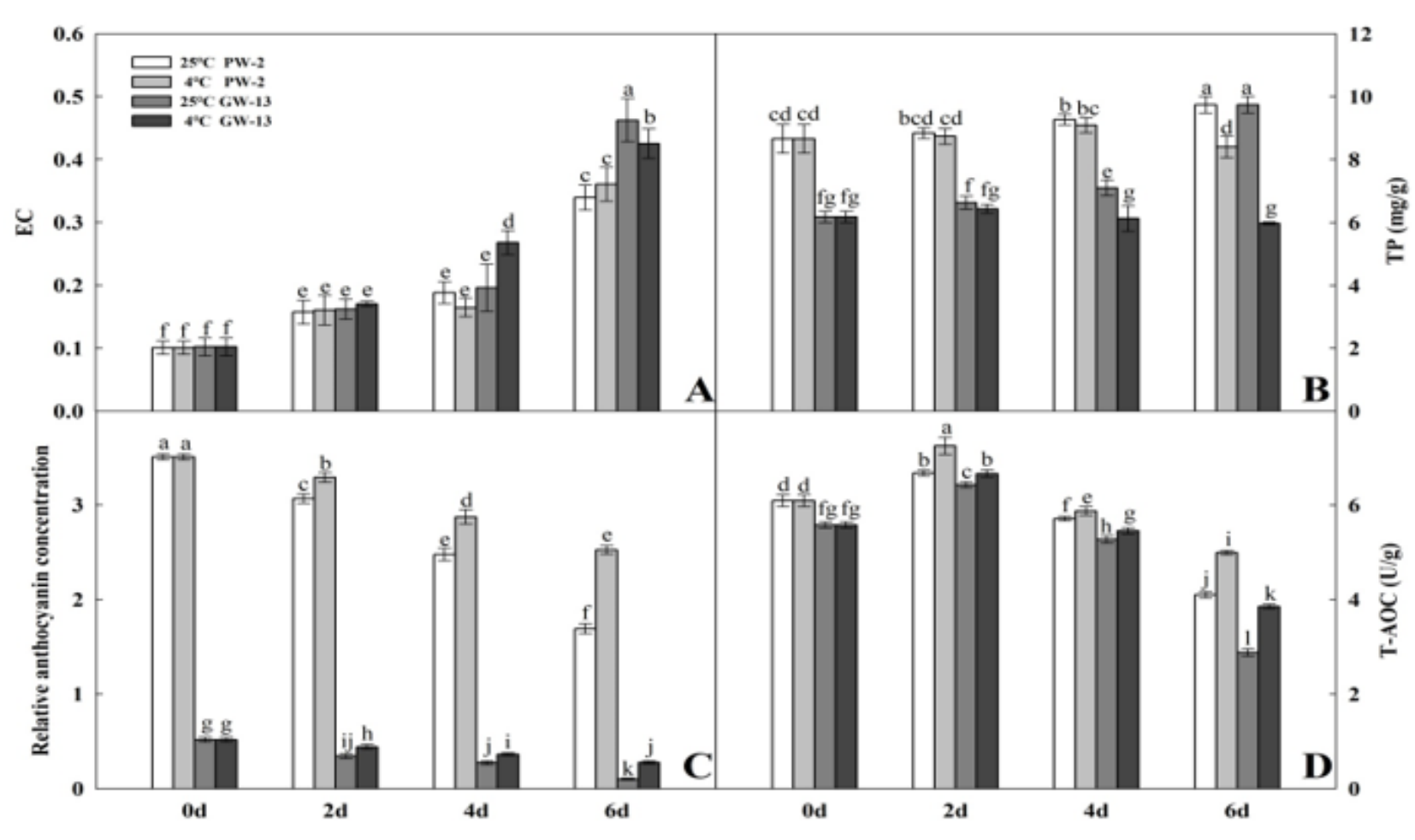

Figure 2:
A. Changes in the value of EC,
B. TP,
C. relative anthocyanin and
D. T-AOC in two wucai genotypes during postharvest storage at different temperatures. Values represent the mean $\pm S E(n$
$=3$ ). Letters indicate significant differences at $\mathrm{P}<0.05$ according to Duncan's multiple range tests. 
The contents of anthocyanin and TP are important indices to evaluate antioxidant capacity of plants [13]. As is well-known that anthocyanin shave antioxidant capability and have been considered as therapeutic agents due to their beneficial health effects including preventing or lowering the risk of cardiovascular disease, inflammation, diabetes, and cancer [14]. Our observations on relative anthocyanin concentration suggested that the relative anthocyanin concentration in PW-2 was 6.79 times higher than GW13 (Figure 2C). It should be the reason that leaf color of two wucai genotypes was significantly different. The relative anthocyanin concentration of two wucai was decreased with the storage period increased, and $4^{\circ} \mathrm{C}$ storage was conducive to alleviating anthocyanin degradation. Similar results as ours were observed in toon sprout [15] and Japanese parsley [16], suggesting that low temperature storage could alleviate pigment degradation of wucai and keep its good leaf color and nutrient value.

T-AOC of PW-2 and GW-13 reached peak value after at 2d, then they exhibited decrease trends with the storage period increased (Figure 2D). And the T-AOC of both genotypes at $4^{\circ} \mathrm{C}$ was significantly higher than at $25^{\circ} \mathrm{C}$. Obviously, the T-AOC in PW-2 at $25^{\circ} \mathrm{C}$ or $4^{\circ} \mathrm{C}$ showed significant increases than that in GW-13. Antioxidant is an important step to prevent aging, because free radicals or oxidants will decompose cells and tissues, affect metabolic function, and cause different health problems [17]. If excessive oxidative free radicals can be eliminated, many free radical-induced and aging- related diseases can be prevented. In our study, the T-AOC of PW-2 was stronger than GW-13 (Figure 2D). And both change trends were rose firstly then declined, which was same to the previous report in wheat [18] and grape [19].

\section{Quality Changes in two Genotypes Wucai}

The contents of Vc, free amino acids, cellulose and total soluble sugar are four important indices to evaluate characteristics of plants. The Vc content of PW-2 was always higher than that in GW13 at all storage conditions (Figure 3A). Furthermore, compared to $25^{\circ} \mathrm{C}$, the Vc content was enhanced when it was stored at $4{ }^{\circ} \mathrm{C}$, which suggested that storage temperature may have a noteworthy impact on Vc levels. Vc is one of the most important nutritional quality parameters in crops and is an essential nutrient for the human body, owing to its beneficial roles as an antioxidant and enzyme cofactor in human health [20]. More than $90 \%$ of the Vc in human diets is supplied by fruits and vegetables, particularly by leafy vegetables [20]. The present study also showed a high amount of Vc in wucai, especially in PW-2 (Figure 3A). Tsaniklidis et al. [21] reported both attached fruits and cold treated fruits retain their Vc levels suggesting that harvesting time is a crucial point for Vc concentration. The Vc content was decreased with the storage period increased in PW-2 and GW-13. Akan et al. [22] also reported $\mathrm{Vc}$ is easily oxidized owing to ascorbic acid oxidase, phenolase and peroxidase enzymes. Therefore, the declined Vc content might be attributed to oxidative stress during storage.

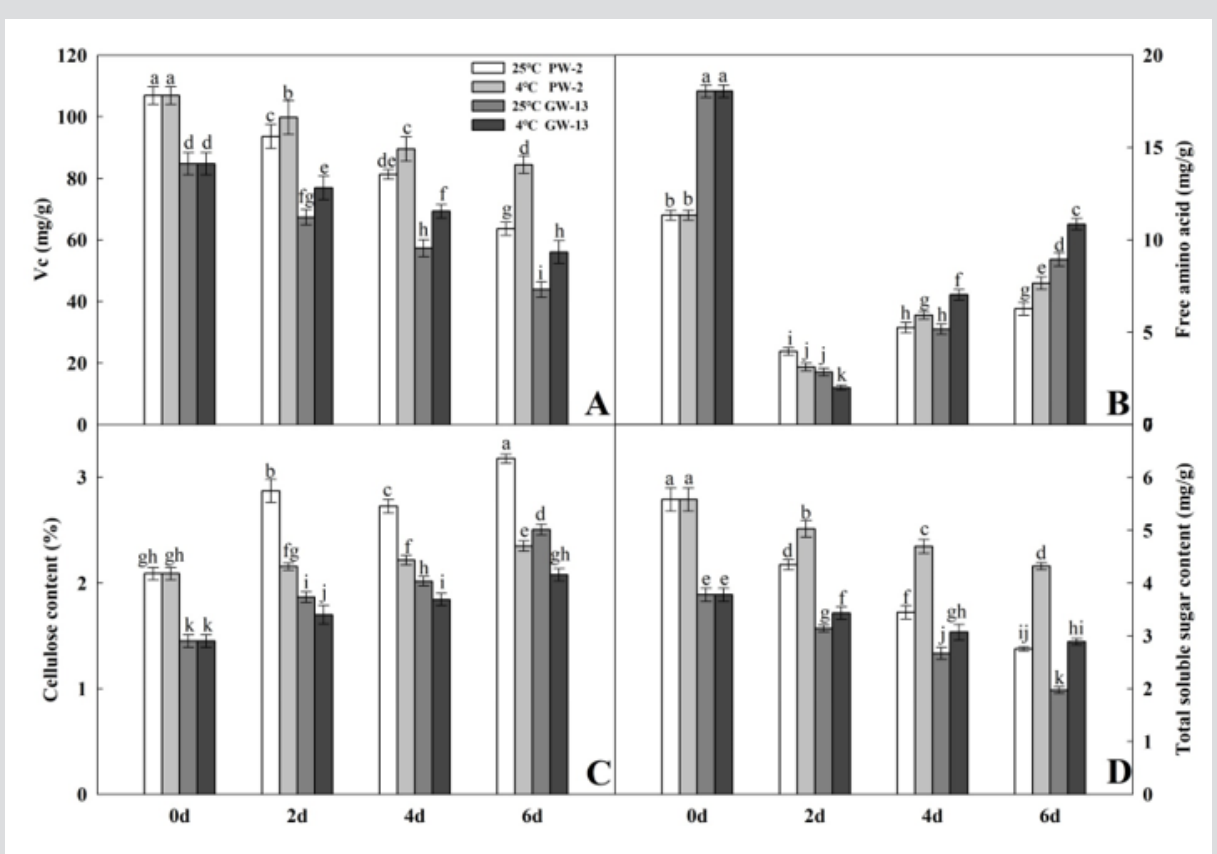

Figure 3:

A. Changes in the content of $\mathrm{Vc}_{\text {, }}$

B. free amino acid,

C. cellulose and

D. total soluble sugar content in two wucai genotypes during postharvest storage at different temperatures. Values represent the mean $\pm S E(n=3)$. Letters indicate significant differences at $P<0.05$ according to Duncan's multiple range tests. 
The free amino acids content in PW-2 was significantly lower than that in GW-13 before storage (Figure 3B). The content of free amino acids in two wucai genotypes reached its lowest level after stored for $2 \mathrm{~d}$, and they were increased gradually with the storage period increased. Free amino acids content in two wucai genotypes stored at $4^{\circ} \mathrm{C}$ was higher than that was stored at $25^{\circ} \mathrm{C}$ at $6 \mathrm{~d}$. They are components of key molecules in higher plants, which not only provide nitrogen, but also have osmoregulation influences on physiological metabolism [23]. Vegetables are good sources of all essential amino acids required for humans, but some vegetables may contain the trace amounts of essential amino acids [24]. In our study, the content of free amino acids in GW-13 was higher than that in PW-2, significantly (Figure 3B). The trends of free amino acid in two wucai genotypes were decreased firstly then slowly increased in entire postharvest storage period, indicating amino acids functioned as osmolyte responding oxidative stress [25]. Furthermore, we observed that $4{ }^{\circ} \mathrm{C}$ could slow down free amino acids loss during storage period.

The cellulose content of PW-2 was significantly higher than that in GW-13 under normal condition (Figure 3C). The cellulose content of PW-2 andGW-13 were increased with the storage period prolonged. This was consistent with previous research on green asparagus (Asparagus officinalis) [25]. In the whole storage period, the cellulose content of PW-2 was always higher than that of GW13 under whatever the storage conditions. Previous studies have confirmed that could function as structural elements of the cell wall, as well as a form of energy storage. That was attributed to an oxidation crosslinking reaction among cellulose, hemicellulose, and polyphenols that occurs during postharvest storage. The cross linking reaction led to the incorporation of lignin, which prevented freezing damage and cell collapse [2]. The combination of cellulose, cross-linking hemicelluloses and interpenetrating pectin provides strength and rigidity to the plant cell walls, which make it highly resistant to mechanical and chemical degradation [26].

The total soluble sugar content was decreased with the storage period prolonged (Figure 3D). The content of total soluble sugar in two wucai genotypes that stored at $4^{\circ} \mathrm{C}$ was markedly higher than that at $25^{\circ} \mathrm{C}$. In the whole storage period, the total soluble sugar content in PW-2 was always higher than GW-13. Likewise, there is reportedly an increase in the content of total soluble sugar with cold temperatures in Allium cepa L. [17], Toonasinensis [15] and Dendrobium officinale [2]. Soluble total sugar is considered important factors related to chilling adaptation in plants and fruits, and it has recently been proposed that sugars can act as real ROS scavengers in plants, especially when present at higher concentrations [27].

\section{Conclusion}

In summary, $\mathrm{PW}-2$ performed better than GW-13 in morphology after low temperature. Our results demonstrated that there were significant differences in antioxidant capacity and quality between the two wucai genotypes. The content of TP, anthocyanin and T-AOC in PW-2 was significantly higher than those in GW-13 before storage. And the content of $\mathrm{Vc}$, total soluble sugar and cellulose in PW-2 were significantly higher than those in GW-13. It showed the antioxidant capacity and nutritional quality of PW-2 could be kept higher than that of GW-13. PW-2 Chl content was higher than that of GW-13 in the $4^{\circ} \mathrm{C}$ storage environment, but the content of the Car is under the two wucai genotypes had the same change trend. And antioxidant capacity of two wucai genotypes that stored at $4^{\circ} \mathrm{C}$ was higher than those stored at $25^{\circ} \mathrm{C}$. In addition, the content of $\mathrm{Vc}$, total soluble sugar, cellulose, TP, T-AOC and anthocyanin PW-2 were significantly higher than those in $\mathrm{GW}-13$ under $4{ }^{\circ} \mathrm{C}$ storage. The EC of PW-2 was always lower than GW-13 during storage. Therefore, low temperature storage is used as an approach to enhance the content of T-AOC total soluble sugar, Vc, TP, total free amino acid and cellulose and extend the shelf-life of wucai.

\section{Acknowledgment}

This work was funded by National Key R \& D Program of China (2017YFD0101803), National Natural Science Foundation of China (No. 31701910), Major Science and Technology Projects of Anhui Province, China (17030701013).

\section{Author Contribution}

Lingyun Yuan, Chenggang Wang and Libing Nie designed the experiment and wrote the manuscript. Shilei Xie, Yun Dai, Jie Wang, Yushan Zheng, Qiang Ji and Mengru Zhao carried out the experiments. Shidong Zhu, Guohu Chen and Jinfeng Hou supervised the study and helped perform the experiments. All authors have read and approved the final manuscript.

\section{References}

1. Yoon YE, Kuppusamy S, Cho KM, Kim PJ, Kwack YB, et al. (2017) Influence of cold stress on contents of soluble sugars, vitamin $\mathrm{C}$ and free amino acids including gamma-aminobutyric acid (GABA) in spinach (Spinaciaoleracea). Food Chemistry 215: 185-192.

2. Yu Z, Yang Z, Teixeira da Silva JA, Luo J, Duan J (2019) Influence of low temperature on physiology and bioactivity of postharvest Dendrobium officinale stems. Postharvest Biology and Technology 148: 97-106.

3. Yuan L, Tang L, Zhu S, Hou J, Chen G, et al. (2017) Influence of heat stress on leaf morphology and nitrogen-carbohydrate metabolisms in two wucai (Brassica campestris L.) genotypes. ActaSoc Bot Pol 86(2): 3554.

4. Dai Y, Yuan L, Zhang S, Wang J, Xie S, et al. (2019) Comprehensive evaluation for cold tolerance in wucai (Brassica campestris L.) by the performance index on an absorption basis (PIabs). Agronomy 9(2): 61.

5. Wang QS, Zhang X, Li CY, Liu ZY, Feng H (2014) Directional transfer of a multiple-allele male sterile line in Brassica campestris L. ssp. chinensis (L.) Makino var. rosularis Tsen et Lee. Breeding Science 64(2): 149-155.

6. Wang Y, Hu L, Liu G, Zhang DS, He HJ (2017) Evaluation of the nutritional quality of Chinese kale (Brassica alboglabra Bailey) using UHPLCQuadrupole-Orbitrap MS/MS-based metabolomics. Molecules 22(8): 1262.

7. Zou M, Yuan L, Zhu S, Liu S, Ge J, et al. (2016) Effects of heat stress on photosynthetic characteristics and chloroplast ultrastructure of a heatsensitive and heat-tolerant cultivar of wucai (Brassica campestris L.) Acta Physiologiae Plantarum 39(1): 30. 
8. Bajji M, Kinet JM, Lutts S (2002) The use of the electrolyte leakage method for assessing cell membrane stability as a water stress tolerance test in durum wheat. Plant Growth Regul 36(1): 61-70.

9. Li H, Huang W, Wang GL, Wang WL, Cui X, et al. (2017) Transcriptomic analysis of the biosynthesis, recycling, and distribution of ascorbic acid during leaf development in tea plant (Camellia sinensis (L.) O. Kuntze). Scientific Reports 7: 46212.

10. Kurubas MS, Maltas AS, Dogan A, KaplanM, Erkan M (2019) Comparison of organically and conventionally produced Batavia type lettuce stored in modified atmosphere packaging for postharvest quality and nutritional parameters. Journal of the Science of Food and Agriculture 99(1): 226-234.

11. Mercado Silva E, Benito Bautista P, de los Angeles García Velasco M (1998) Fruit development, harvest index and ripening changes of guavas produced in central Mexico. Postharvest Biology and Technology 13(2): 143-150.

12. Campos PS, Quartin V, Ramalho JR, chicho, Nunes MA (2003) Electrolyte leakage and lipid degradation account for cold sensitivity in leaves of Coffea sp. plants. Journal of Plant Physiology 160(3): 283-292.

13. He F, Chen J, Dong K, Leng Y, Xu J, et al. (2018) Multi-technical analysis on the antioxidative capacity and total phenol contents of 94 traditional Chinese dietary medicinal herbs. Food Science \& Nutrition 6(6): 13581369.

14. Zhang Y, Liu Y, Hu W, Sun B, Chen Q, et al. (2018) Anthocyanin accumulation and related gene expression affected by low temperature during strawberry coloration. Acta Physiologiae Plantarum 40(11): 192.

15. Hu Z, Weijian L, Yali F, Huiquan L (2018) Gibberellic acid enhances postharvest toon sprout tolerance to chilling stress by increasing the antioxidant capacity during the short-term cold storage. Scientia Horticulturae 237: 184-191.

16. Hasegawa H, Fukasawa Akada T, Okuno T, Niizeki M, Suzuki M (2001) Anthocyanin accumulation and related gene expression in Japanese parsley (Oenanthe stolonifera DC.) induced by low temperature. Journal of Plant Physiology 158(1): 71-78.

17. Benkeblia N, Shiomi N (2004) Chilling effect on soluble sugars, respiration rate, total phenolics, peroxidase activity and dormancy of onion bulbs. Scientia Agricola 61(3): 281-285.

\section{ISSN: 2574-1241}

DOI: 10.26717/BJSTR.2019.15.002676

Lingyun Yuan, Chenggang Wang. Biomed J Sci \& Tech Res

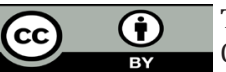

This work is licensed under Creative

Commons Attribution 4.0 License

Submission Link: https://biomedres.us/submit-manuscript.php
18. Li X, Topbjerg HB, Jiang D, Liu F (2015) Drought priming at vegetative stage improves the antioxidant capacity and photosynthesis performance of wheat exposed to a short-term low temperature stress at jointing stage. Plant and Soil 393(1-2): 307-318.

19. Romero I, Sanchez Ballesta MT, Escribano MI, Merodio C (2008) Individual anthocyanins and their contribution to total antioxidant capacity in response to low temperature and high $\mathrm{CO}_{2}$ in stored Cardinal table grapes. Postharvest Biology and Technology 49 (1): 1-9.

20. Young VR, Pellett PL (1994) Plant proteins in relation to human protein and amino acid nutrition. The American Journal of Clinical Nutrition 59(5): 1203S-1212S.

21. Tsaniklidis G, Delis C, Nikoloudakis N, Katinakis P, Aivalakis G (2014) Low temperature storage affects the ascorbic acid metabolism of cherry tomato fruits. Plant Physiology and Biochemistry 84: 149-157.

22. Akan S, TunaGunes N, Yanmaz R (2019) Methyl jasmonate and low temperature can help for keeping some physicochemical quality parameters in garlic (Allium sativum L.) cloves. Food Chemistry 270: 546-553.

23. Song J, Liu C, Li D, Gu Z (2015) Postharvest changes in physicochemical characteristics and free amino acids content of immature vegetable soya bean (Glycine max L.) grains. International Journal of Food Science \& Technology 51(2): 461-469.

24. Qiu M, Wu C, Ren G, Liang X, Wang X, et al. (2014) Effect of chitosan and its derivatives as antifungal and preservative agents on postharvest green asparagus. Food Chemistry 155: 105-111.

25. Barberis A, Cefola M, Pace B, Azara E, Spissu Y, et al. (2019) Postharvest application of oxalic acid to preserve overall appearance and nutritional quality of fresh-cut green and purple asparagus during cold storage: a combined electrochemical and mass-spectrometry analysis approach. Postharvest Biology and Technology 148: 158-167.

26. Neugart S, Baldermann S, Hanschen FS, Klopsch R, Wiesner Reinhold M, et al. (2018) The intrinsic quality of brassicaceous vegetables: How secondary plant metabolites are affected by genetic, environmental, and agronomic factors. Scientia Horticulturae 233: 460-478.

27. Palma F, Carvajal F, Lluch C, Jamilena M, Garrido D (2014) Changes in carbohydrate content in zucchini fruit (Cucurbita pepo L.) under low temperature stress. Plant Science 217-218: 78-86.

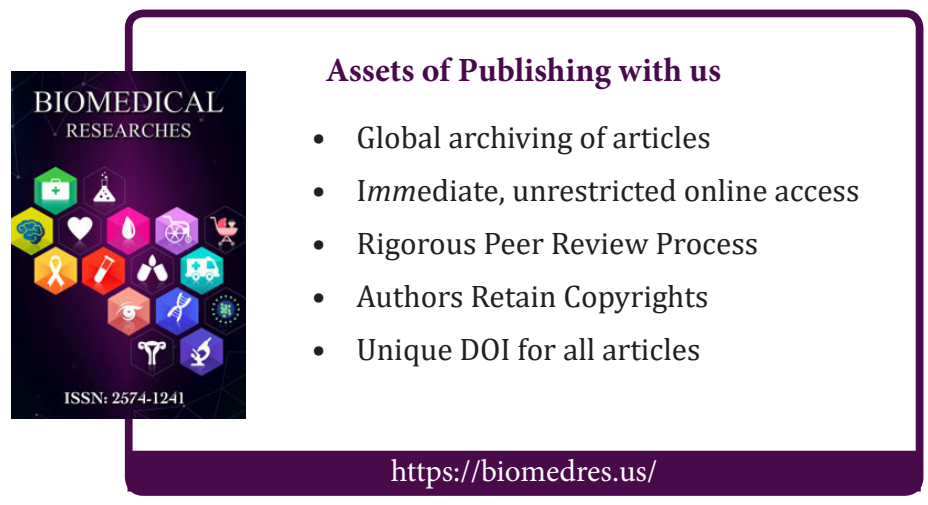

Copyright@ Lingyun Y, Chenggang W| Biomed J Sci \& Tech Res| BJSTR. MS.ID.002676. 